\title{
Health Status Inequality among Immigrants in Switzerland
}

\author{
Thomas Volken*, Peter Rüesch \\ School of Health Professions, Zurich University of Applied Sciences Technikumstrasse, Winterthur, Switzerland \\ Email: ${ }^{*}$ thomas.volken@zhaw.ch, peter.rueesch@zhaw.ch
}

Received 8 April 2014; revised 18 May 2014; accepted 11 June 2014

Copyright $@ 2014$ by authors and Scientific Research Publishing Inc.

This work is licensed under the Creative Commons Attribution International License (CC BY). http://creativecommons.org/licenses/by/4.0/

c) (i) Open Access

\begin{abstract}
Objective: To assess self-rated health and impairments for six large immigrant groups (Germany, Italy, Kosovo, Portugal, Serbia, Turkey) in Switzerland. Methods: We used population-based survey data from the Swiss Migrant Health Survey 2010 and the Swiss Health Survey 2007. The sample comprised permanent residents aged 17 - 64 years $(n=14,637)$. Multivariate logistic regressions have been used to estimate odds ratios (OR). Results: Ill health and activities of daily living (ADL) impairments were associated with older age in all groups. However, nationals from Turkey and nationals from Kosovo were substantially more likely than Swiss to report ill health $(\mathrm{OR}=1.05$; $\mathrm{CI}$ $=1.02$ - 1.09; $P=0.001$ and $O R=1.05 ; C I=1.01-1.10 ; P=0.016)$ and $A D L$ impairments $(O R=1.06$; $\mathrm{CI}=1.03-1.09 ; \mathrm{P}=0.000$ and $\mathrm{OR}=1.04 ; \mathrm{CI}=1.01-1.07 ; \mathrm{P}=0.004)$ with increasing age. Furthermore, Portuguese women were more likely $(\mathrm{OR}=2.65 ; \mathrm{CI}=1.40-5.03 ; \mathrm{P}=0.003)$ to report ill health than Swiss women. Conclusions: Immigrant-specific preventive and health promotion initiatives should target vulnerable immigrants from Turkey, Portugal, and Kosovo. Furthermore, groups with few economic and psychosocial resources in the general population of Switzerland should be more involved in interventions to reduce health risk.
\end{abstract}

\section{Keywords}

Health Status, Impairment, Immigrant, Switzerland

\section{Introduction}

In the context of immigration, ethnicity and country of origin has been shown to be associated with unfavourable environmental health conditions, health opportunities, health behaviour and health outcomes. More specifically, evidence suggests that immigrant status is associated with health adverse working conditions [1] [2]. With

${ }^{*}$ Corresponding author. 
respect to health opportunities, several studies find poor health literacy, poor access to health services or poor utilization of health services among immigrants as compared to natives [3]-[7]. Evidence of unfavourable health behaviour of immigrants, such as lack of physical activity and unhealthy dietary habits and resulting risk factors such as overweight and obesity [8]-[12], has also been documented. Furthermore, studies report poorer health status, higher morbidity and higher mortality among immigrants [13]-[18]. On the other hand, studies also find better health status, lower morbidity and lower mortality [19]-[21], lower risks of overweight and obesity [22] [23] and healthier dietary habits [24]-[28] in immigrant populations as compared to the native population of the host country. Finally, some studies present mixed evidence, i.e. they find that health risks [29] [30] and health outcomes [31]-[37] are unevenly distributed among immigrant groups. The different results can be largely attributed to the specific immigrant group(s) under study as well as to the context (host country) in which immigration took place. For example, self-reported health of German and French immigrants in Switzerland did not significantly differ from the majority of Swiss whereas immigrants from Italy, Portugal, Spain, Turkey and the Former Yugoslavia reported lower levels of health [14]. In Australia, on the other hand, Mediterranean immigrants had particularly favourable health outcomes, and Italian and Greek immigrants were found to have the greatest health advantage [19].

These findings suggest that immigrant groups may be very heterogeneous in some host countries and that the conventional Western conception of immigrants as vulnerable individuals characterized by low socio-economic status, working in unhealthy jobs, having poor health literacy and poor access to health services etc., may not necessarily be generalized. Established theoretical explanations on migration and health can account for such differences: social and cultural patterns from the country of origin shape physical activity, body images, dietary intake and food preferences [38]-[44] and entail general health advantages or disadvantages [45]. However, the impact of the culture of origin potentially diminishes over time since immigrants tend to adopt beliefs, values and norms of the host country, i.e. the health behaviour of immigrants converges towards the health behaviour of the native population in a process of acculturation [45]. Despite the fact that theoretical explanations and empirical evidence suggest differentiated analyses of immigrant groups and the need for boosted samples of minority groups in health surveys [46] [47] has been recognized, no immigrant-specific population-based study has so far assessed the self-rated health status and activities of daily living (ADL) impairments of adult immigrants in Switzerland. In 2009, immigrants accounted for 1.7 million people or $22 \%$ of the permanent resident population of Switzerland [48]. Immigrants are an important group and prevention campaigns may need to be tailored to specific immigrant groups and their needs. The aim of this study is to assess the risk of ill health and ADL impairment among six large immigrant groups (country of origin) in Switzerland and thereby serve as a guide for identifying vulnerable immigrant groups that may be addressed with adequate preventive and health promotion initiatives.

\section{Methods}

\subsection{Study Design}

The study is a population-based cross-sectional health survey carried out in 2007 and 2010 in Switzerland.

\subsection{Study Population and Data}

Data from the Swiss Immigrant Health Survey 2010 (SMHS) and the Swiss Health Survey 2007 (SHS) were obtained from the Swiss Federal Office of Public Health. The SMHS is a cross-sectional, population-based telephonic survey which intends to monitor health trends in a representative sample of immigrants and has been carried out in 2004 and 2010 so far. Due to economic constraints, the SMHS is limited to a selected number of nationalities. The core study population 2010 comprises permanent residents from Portugal, Turkey, Serbia and Kosovo $(n=1800)$. Participants aged 17 - 74 were chosen by stratified random sampling (gender, country of birth, duration of stay) from the database of the central immigration information system. The computer-aided telephone interviews were carried out in Portuguese, Turkish, Serbian, Albanian, German, and French. Data of Swiss, German and Italian nationals from the SHS 2007 were pooled with the SMHS data. The SHS intends to monitor health trends in a representative sample of all permanent residents in Switzerland. It was first conducted in 1992 and is repeated every five years. The 2007 sample included over 19,000 subjects aged 15 years or older. 
Subjects were randomly selected within private households and computer-aided telephone interviews were conducted in German, French and Italian. People who did not speak any of these languages or people who had insufficient language skills were excluded from the SHS. Immigrant participants in both surveys include immigrants and their children, i.e. permanent residents with a non-Swiss nationality.

The response rate of those in the initial SHS sample was $66.2 \% .13 .2 \%$ could not be contacted after numerous contact attempts and $20.6 \%$ refused to participate in the SHS. In the initial SMHS national samples, the response rates of nationals from Kosovo, Portugal, Serbia, and Turkey were 50.1\%, 51.0\%, 46.9\%, and 50.8\% respectively. 35.2\% of nationals from Kosovo, 36.4\% from Portugal, 30.8\% from Serbia and 33.0\% from Turkey could not be contacted after numerous contact attempts and $14.7 \%, 12.6 \%, 22.3 \%$ and $16.2 \%$ refused to participate in the SMHS.

In the SMHS, contact attempts were less successful and refusals-with the exception of nationals from Serbia -were less likely as compared to the SHS. Several factors may account for these differences. First, subjects in the SMHS were contacted and interviews conducted in their respective native language whereas subjects in the SHS had to have sufficient French, German or Italian language skills in order to participate. Selection bias due to insufficient language skills may have been mitigated in the SMHS, i.e. refusal rates were lower because the selection process is less likely to favour immigrants who are well-integrated, well-educated and have been living in Switzerland for a long period of time. Second, potential SMHS participants may have been more difficult to contact because they were younger on average and younger subjects may tend to spend more time outside their homes (school, work, leisure). However, we have no data to substantiate these hypotheses because nationality and other important sociodemographic characteristics were not recorded for the initial SHS and SMHS samples.

The pooled sample represents $58.2 \%$ of the immigrant population as well as nationals from Switzerland. Of the 1.7 million immigrants in Switzerland, $17.0 \%$ are Italian, $14.9 \%$ are German, $12.0 \%$ are Portuguese, 5.4\% are French, 3.6\% are Spaniards, 6.9\% are from Serbia, 4.1\% are Turkish and 3.3\% are from Kosovo [48]. Immigrants from France and Spain were not included because of their small sample size in the SHS. All interviews of the subjects in the pooled sample were conducted in their respective native language.

For the purpose of this study, the initial pooled sample was further narrowed down to include only subjects 17 - 64 years old because only few immigrants in the SMHS sample were over 64 years old. The total sample size amounts to 14,637. The sample size by nationality and further characteristics of the pooled SMHS and SHS sample is shown in Table 1.

\subsection{Target Outcomes, Predictor and Covariates}

Health status, the first target outcome of this study, was derived from self-reported data. Participants were asked to report their health by answering the question: "In general, how would you rate your health? (very good, good, fair, poor, very poor)". Subjects who rated their health status as fair, poor or very poor were assigned to the ill health category, subjected who rated their health status as very good or good were assigned to the good health category. ADL impairments, the second target outcome of this study, was also derived from self-reported data. Participants were asked to report ADL impairment within the last 6 months by answering the question: "During the last six months, how much have you been limited by a health problem in your activities of daily living? (not at all limited, somewhat limited, severely limited)". Subjects who reported to be somewhat or severely limited were then assigned to the category with and the remaining subjects to the category without ADL impairments.

For the primary predictor, the country of origin, the following nationalities were considered: Portugal, Turkey, Serbia, Kosovo, Germany, Italy and Switzerland. Double citizens who acquired the Swiss nationality through naturalization were considered Swiss. Covariates included: age (measured in whole years), gender (male/female), socio-economic status (SES) and dwelling zone. SES comprised three indicators: education (basic, secondary, and university), employment (economically active [no/yes]), and housing situation (rooms per person). Urbanity comprised two categories: rural area and urban area. Urban areas included isolated cities ( $\geq 10,000$ inhabitants) and urban agglomerations ( $\geq 20,000$ inhabitants); all other areas were assigned to the category rural area. Furthermore, two psychosocial resources—sense of mastery and social support-were selected as covariates because of their relevance when coping with stressful life events such as diseases and impairment [49]. While the sense of mastery instrument was based on a brief version of the Pearlin coping questionnaire [50], the social support instrument was based on the SMHS 5-item social support index. 
Table 1. Frequency distribution and central tendency for variables in the sample of subjects aged 17 - 64 years by nationality (Swiss Immigrant Health Survey 2010 \& Swiss Health Survey 2007).

\begin{tabular}{|c|c|c|c|c|c|c|c|}
\hline $\mathrm{N}=14,637$ (sample size) & $\begin{array}{c}\text { Portugal } \\
\text { (449) }\end{array}$ & $\begin{array}{l}\text { Turkey } \\
\text { (644) }\end{array}$ & $\begin{array}{l}\text { Serbia } \\
\text { (455) }\end{array}$ & $\begin{array}{c}\text { Kosovo } \\
\text { (648) }\end{array}$ & $\begin{array}{c}\text { Germany } \\
\text { (324) }\end{array}$ & $\begin{array}{l}\text { Italy } \\
(369)\end{array}$ & $\begin{array}{c}\text { Switzerland } \\
(11,748)\end{array}$ \\
\hline & $\%$ & $\%$ & $\%$ & $\%$ & $\%$ & $\%$ & $\%$ \\
\hline \multicolumn{8}{|l|}{ Self-reported health ${ }^{\mathrm{b}}$} \\
\hline Very good, good, fair & 80.1 & 77.9 & 84.8 & 90.4 & 94.4 & 79.9 & 89.7 \\
\hline Poor, very poor & 19.9 & 22.1 & 15.2 & 9.6 & 5.6 & 20.1 & 10.3 \\
\hline \multicolumn{8}{|l|}{ ADL impairment } \\
\hline Not at all limited & 81.7 & 68.5 & 74.2 & 80.1 & 74.2 & 74.4 & 76.6 \\
\hline Somewhat/severely limited & 18.3 & 31.5 & 25.8 & 19.9 & 25.8 & 25.6 & 23.4 \\
\hline \multicolumn{8}{|l|}{ Gender } \\
\hline Male & 50.1 & 50.0 & 49.9 & 49.7 & 51.9 & 55.3 & 45.9 \\
\hline Female & 49.9 & 50.0 & 50.1 & 50.3 & 48.1 & 44.7 & 54.1 \\
\hline \multicolumn{8}{|l|}{ Education } \\
\hline Basic & 55.9 & 40.2 & 30.6 & 46.8 & 1.5 & 24.9 & 7.4 \\
\hline Secondary & 37.0 & 38.2 & 56.4 & 49.8 & 37.7 & 61.8 & 63.5 \\
\hline University & 7.1 & 21.6 & 13.0 & 3.4 & 60.8 & 13.3 & 29.1 \\
\hline Economically active & 82.2 & 53.0 & 75.0 & 59.9 & 88.3 & 75.1 & 79.7 \\
\hline \multicolumn{8}{|l|}{ Urbanity $^{\mathrm{d}}$} \\
\hline Urban area & 78.2 & 88.5 & 82.4 & 74.7 & 76.5 & 83.5 & 66.0 \\
\hline Rural area & 21.8 & 11.5 & 17.6 & 25.3 & 23.5 & 16.5 & 34.0 \\
\hline \multicolumn{8}{|l|}{ Sense of mastery ${ }^{\mathrm{e}}$} \\
\hline Low & 22.8 & 22.8 & 20.6 & 13.8 & 16.9 & 30.7 & 21.6 \\
\hline Medium & 32.6 & 28.0 & 27.8 & 17.0 & 38.7 & 36.9 & 42.3 \\
\hline High & 44.6 & 49.2 & 51.6 & 69.2 & 44.4 & 32.4 & 36.1 \\
\hline \multicolumn{8}{|l|}{ Length of residence $^{\mathrm{f}}$} \\
\hline$<10$ years & 49.7 & 62.0 & 48.1 & 62.2 & 63.3 & 9.7 & \\
\hline $10-19$ years & 28.5 & 13.8 & 30.8 & 29.9 & 18.8 & 7.2 & \\
\hline \multirow[t]{2}{*}{$\geq 20$ years } & 21.8 & 24.2 & 21.1 & 7.9 & 17.9 & 83.1 & \\
\hline & $\begin{array}{l}\text { mean } \\
(\mathrm{SD})\end{array}$ & $\begin{array}{l}\text { mean } \\
(\mathrm{SD})\end{array}$ & $\begin{array}{l}\text { mean } \\
(\mathrm{SD})\end{array}$ & $\begin{array}{l}\text { mean } \\
(\mathrm{SD})\end{array}$ & $\begin{array}{l}\text { mean } \\
(\mathrm{SD})\end{array}$ & $\begin{array}{l}\text { mean } \\
(\mathrm{SD})\end{array}$ & $\begin{array}{l}\text { mean } \\
(\mathrm{SD})\end{array}$ \\
\hline Age (years) & $\begin{array}{c}35.6 \\
(12.2)\end{array}$ & $\begin{array}{c}33.8 \\
(10.5)\end{array}$ & $\begin{array}{c}33.3 \\
(12.4)\end{array}$ & $\begin{array}{c}29.0 \\
(10.7)\end{array}$ & $\begin{array}{c}40.8 \\
(10.7)\end{array}$ & $\begin{array}{c}43.1 \\
(11.9)\end{array}$ & $\begin{array}{c}43.0 \\
(13.0)\end{array}$ \\
\hline Housing (rooms/person) & $\begin{array}{l}1.1 \\
(0.6)\end{array}$ & $\begin{array}{c}1.2 \\
(0.5)\end{array}$ & $\begin{array}{c}1.1 \\
(0.4)\end{array}$ & $\begin{array}{c}0.9 \\
(0.4)\end{array}$ & $\begin{array}{c}2.1 \\
(1.0)\end{array}$ & $1.8(1.0)$ & $\begin{array}{c}2.0 \\
(1.0)\end{array}$ \\
\hline Social support ${ }^{\mathrm{g}}$ & $\begin{array}{c}4.0 \\
(0.7)\end{array}$ & $\begin{array}{c}3.9 \\
(0.8)\end{array}$ & $\begin{array}{c}4.2 \\
(0.6)\end{array}$ & $\begin{array}{c}4.1 \\
(0.6)\end{array}$ & $\begin{array}{c}3.8 \\
(0.6)\end{array}$ & $\begin{array}{c}3.8 \\
(0.8)\end{array}$ & $\begin{array}{c}3.9 \\
(0.7)\end{array}$ \\
\hline
\end{tabular}

${ }^{a}$ Figures refer to percentage or arithmetic mean and standard deviation (SD) within nationality. ${ }^{\mathrm{b}}$ In general, how would you rate your health? (very good, good, fair, poor, very poor). ${ }^{\circ}$ During the last six months, how much have you been limited by a health problem in your activities of daily living? (not at all limited, somewhat limited, severely limited). ${ }^{\mathrm{d}}$ Classification according to the Swiss Federal Statistical Office. Urban areas include isolated cities ( $\geq 10,000$ inhabitants) and urban agglomerations $\left(\geq 20,000\right.$ inhabitants). ${ }^{e}$ Based on the brief version of the Pearlin coping questionnaire. ${ }^{f}$ Number of years passed since immigration to Switzerland (non-Swiss nationals only). ${ }^{\mathrm{g}}$ Based on the SMHS 5-item social support index (higher values indicate more social support).

\subsection{Weighting}

The original expansion weights of the SMHS and SHS were used for all population estimates. The weights take into account the different sampling strategies which have been used to sample immigrants and Swiss nationals and they allow correct estimates of population parameters for immigrants and Swiss nationals.

\subsection{Statistical Analysis}

We used STATA Version 12.1 for all statistical analyses. Multivariate logistic regression was employed to as- 
sess the factors associated with ill health and ADL impairments. We reported adjusted odds ratios (OR), 95\% confidence intervals (CI) and P-values. OR were adjusted for age, gender, the interaction between age and gender, socio-economic status (including educational level, employment, number of rooms/person), nationality, and the interaction between nationality and age and the interaction between nationality and gender. To incorporate information on the appropriate weights and sampling units for correct variance estimation, all statistical analyses were carried out using STATA's command for complex surveys (svy prefix). Statistical significance was established at $\mathrm{P} \leq 0.05$.

\section{Results}

\subsection{Factors Associated with Ill Health}

Adjusting for all covariates, we found no main effect of nationality for men, i.e. immigrant men and Swiss men were equally likely to report ill health where as Portuguese women were more likely and German women were less likely to report ill health than Swiss women (Table 2). Overall, ill health was associated with older age in all groups (Figure 1). However, nationals from Turkey and nationals from Kosovo were substantially more likely than Swiss to report ill health with increasing age. Furthermore, subjects with secondary education or a university degree were less likely to report ill health than those with basic education. Economically active subjects were less likely to report ill health than subjects who were not economically active. Subjects with more social support and those with medium or high sense of mastery were also less likely to report ill health. Finally, neither housing situation nor the specific dwelling zone was significantly associated with ill health.

In order to control for potential acculturation effects, length of time in Switzerland (years) was added as a covariate to the model previously discussed and the model was re-estimated using immigrant data only. However, length of time in Switzerland had no statistically significant association with ill health (results not shown).

\subsection{Factors Associated with ADL Impairment}

Adjusting for all covariates, we found that Turkish men and Portuguese men were less likely to report ADL impairment than Swiss men where as immigrant women from different nationalities and Swiss women showed tistical significance (Table 2). ADL impairments were associated with older age in Swiss men. Swiss women
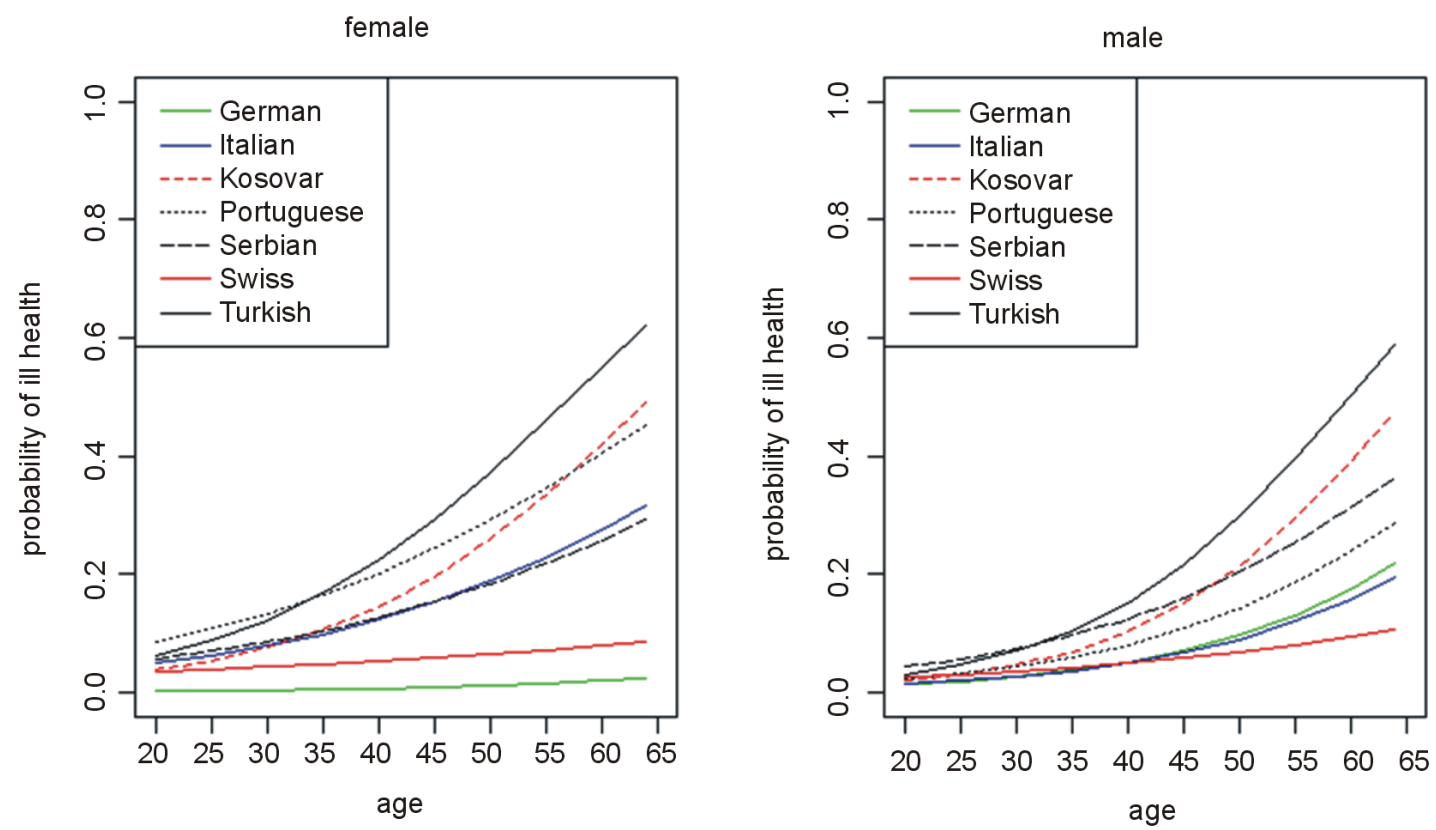

Figure 1. Probability of ill health by age, gender and nationality . * All other covariates held constant (education $=$ secondary, rooms/person $=1.5$, economically active $=$ yes, region $=$ rural area, sense of mastery $=$ medium, social support $=4.0)$. Significant differences between Swiss and immigrants from Turkey $(\mathrm{P}=0.001)$ and immigrants from Kosovo $(\mathrm{P}=0.016)$. 
Table 2. Multivariate logistic regression of ill health and ADL impairments ${ }^{\mathrm{a}}$.

\begin{tabular}{|c|c|c|c|c|c|c|}
\hline & Ill health & & & mpairme & & \\
\hline Variable & OR & $\mathrm{P}>\mathrm{z}$ & $95 \%$ CI & OR & $\mathrm{P}>\mathrm{z}$ & $95 \%$ CI \\
\hline Age & 1.04 & 0.000 & $1.02-1.05$ & 1.01 & 0.007 & $1.00-1.02$ \\
\hline \multicolumn{7}{|l|}{ Gender } \\
\hline Male & 1.00 & reference & & 1.00 & reference & \\
\hline Female & 1.89 & 0.102 & $0.88-4.08$ & 1.36 & 0.184 & $0.86-2.16$ \\
\hline Gender $\times$ age & 0.99 & 0.072 & $0.97-0.00$ & 1.00 & 0.697 & $0.99-1.01$ \\
\hline \multicolumn{7}{|l|}{ Nationality } \\
\hline Swiss & 1.00 & reference & & 1.00 & reference & \\
\hline Portuguese & 0.54 & 0.373 & $0.14-2.08$ & 0.27 & 0.026 & $0.09-0.85$ \\
\hline Turkish & 0.44 & 0.218 & $0.12-1.63$ & 0.23 & 0.007 & $0.08-0.68$ \\
\hline Serbian & 1.12 & 0.876 & $0.28-4.49$ & 2.76 & 0.069 & $0.92-8.26$ \\
\hline Kosovar & 0.28 & 0.216 & $0.04-2.11$ & 0.41 & 0.123 & $0.13-1.27$ \\
\hline German & 0.28 & 0.350 & $0.02-4.12$ & 3.34 & 0.112 & $0.76-14.76$ \\
\hline Italian & 0.32 & 0.345 & $0.03-3.45$ & 0.87 & 0.863 & $0.17-4.38$ \\
\hline \multicolumn{7}{|l|}{ Nationality $\times$ age } \\
\hline Portuguese & 1.03 & 0.055 & $1.00-1.06$ & 1.02 & 0.104 & $1.00-1.05$ \\
\hline Turkish & 1.05 & 0.001 & $1.02-1.09$ & 1.06 & 0.000 & $1.03-1.09$ \\
\hline Serbian & 1.02 & 0.129 & $0.99-1.05$ & 0.98 & 0.123 & $0.96-1.01$ \\
\hline Kosovar & 1.05 & 0.016 & $1.01-1.10$ & 1.04 & 0.004 & $1.01-1.07$ \\
\hline German & 1.03 & 0.263 & $0.98-1.10$ & 0.98 & 0.192 & $0.94-1.01$ \\
\hline Italian & 1.03 & 0.249 & $0.98-1.08$ & 0.99 & 0.767 & $0.96-1.03$ \\
\hline \multicolumn{7}{|l|}{ Nationality $\times$ gender } \\
\hline Portuguese & 2.65 & 0.003 & $1.40-5.03$ & 1.56 & 0.115 & $0.90-2.73$ \\
\hline Turkish & 1.49 & 0.238 & $0.77-2.87$ & 0.78 & 0.377 & $0.45-1.35$ \\
\hline Serbian & 0.93 & 0.866 & $0.42-2.06$ & 1.13 & 0.708 & $0.59-2.16$ \\
\hline Kosovar & 1.37 & 0.502 & $0.54-3.45$ & 0.87 & 0.669 & $0.45-1.67$ \\
\hline German & 0.12 & 0.015 & $0.02-0.66$ & 0.90 & 0.774 & $0.43-1.88$ \\
\hline Italian & 2.49 & 0.061 & $0.96-6.47$ & 1.57 & 0.312 & $0.66-3.74$ \\
\hline \multicolumn{7}{|l|}{ Education } \\
\hline Basic & 1.00 & reference & & 1.00 & reference & \\
\hline Secondary & 0.65 & 0.001 & $0.51-0.83$ & 0.80 & 0.036 & $0.65-0.99$ \\
\hline University & 0.44 & 0.000 & $0.33-0.60$ & 0.79 & 0.044 & $0.62-0.99$ \\
\hline Housing (rooms/person) & 1.02 & 0.689 & $0.93-1.12$ & 1.05 & 0.186 & $0.98-1.12$ \\
\hline \multicolumn{7}{|l|}{ Economically active } \\
\hline No & 1.00 & reference & & 1.00 & reference & \\
\hline Yes & 0.43 & 0.000 & $0.36-0.52$ & 0.63 & 0.000 & $0.55-0.73$ \\
\hline \multicolumn{7}{|l|}{ Urbanity } \\
\hline Urban area & 1.00 & reference & & 1.00 & reference & \\
\hline Rural area & 0.93 & 0.502 & $0.77-1.14$ & 1.02 & 0.766 & $0.89-1.17$ \\
\hline \multicolumn{7}{|l|}{ Sense of mastery ${ }^{\mathrm{b}}$} \\
\hline Low & 1.00 & reference & & 1.00 & reference & \\
\hline Medium & 0.39 & 0.000 & $0.31-0.47$ & 0.66 & 0.000 & $0.57-0.78$ \\
\hline High & 0.24 & 0.000 & $0.19-0.30$ & 0.46 & 0.000 & $0.39-0.54$ \\
\hline Social support ${ }^{\mathrm{c}}$ & 0.72 & 0.000 & $0.63-0.82$ & 0.89 & 0.031 & $0.81-0.99$ \\
\hline Constant & 0.45 & 0.078 & $0.19-1.09$ & 0.66 & 0.172 & $0.37-1.20$ \\
\hline $\mathrm{N}$ & 11,649 & & & 10,714 & & \\
\hline
\end{tabular}

${ }^{a}$ Weighted data of 17 - 64-year-old subjects, Swiss Immigrant Health Survey 2010 \& Swiss Health Survey 2007. Ill health (1/0): $1=$ self-rated health. very poor, poor or fair; $0=$ self-rated health very good or good. Impairment (1/0): $1=$ somewhat/severely limited inactivities of daily living during the last 6 weeks; $0=$ not at all limited. ${ }^{b}$ Based on the brief version of the Pearlin coping questionnaire. ${ }^{\circ}$ Based on the SMHS 5-item social support index (higher values indicate more social support). 
similar odds of reporting ADL impairments, i.e. none of the nation-specific odds ratios for women attained stawere equally likely to report ADL impairments with increasing age. However, nationals from Turkey and nationals from Kosovo were substantially more likely than Swiss to report ADL impairments with increasing age (Figure 2). Furthermore, subjects with secondary education or a university degree were less likely to report ADL impairments than those with a basic education. Economically active subjects were less likely to report ADL impairments than subjects who were not economically active. Subjects with more social support and those with medium or high sense of mastery were also less likely to report ADL impairments. Finally, neither housing situation nor the specific dwelling zone was significantly associated with ADL impairments. Again, length of time in Switzerland (years) was added as a covariate to the model previously discussed and the model was reestimated using immigrant data only. Length of time in Switzerland had no statistically significant association with ADL impairments (results not shown).

\section{Discussion}

So far, population-based studies on health status and ADL impairments among immigrants in Switzerland are rare and have been based mainly on data of the SHS [51]. However, the SHS data has limitations with regard to the study of immigrants. First, interviews are only carried out in German, French and Italian. Second, the sampling process does not include any immigrant-specific characteristics, e.g. the country of origin. Consequently, the SHS data potentially favours well-integrated, well-educated and well-assimilated immigrants and potentially omits vulnerable groups of immigrants. Furthermore, the sample size for specific groups of immigrants, e.g. Turkish immigrants, tends to be very small.

To our knowledge, the present study is the first study which used the SMHS 2010 data to assess self-reported health and ADL impairments among immigrants and hence used a survey which had been especially designed to collect public health related data on immigrants in Switzerland. Since all SMHS interviews were conducted in the subjects' respective native languages, selection bias due to insufficient language skills has been mitigated.

Overall, we found that ill health and ADL impairments were unevenly distributed among immigrants in Switzerland. Turkish and Kosovar immigrants were consistently more likely to report ill health and ADL impairments than Swiss with increasing age, i.e. older immigrants from these two countries more often than Swiss
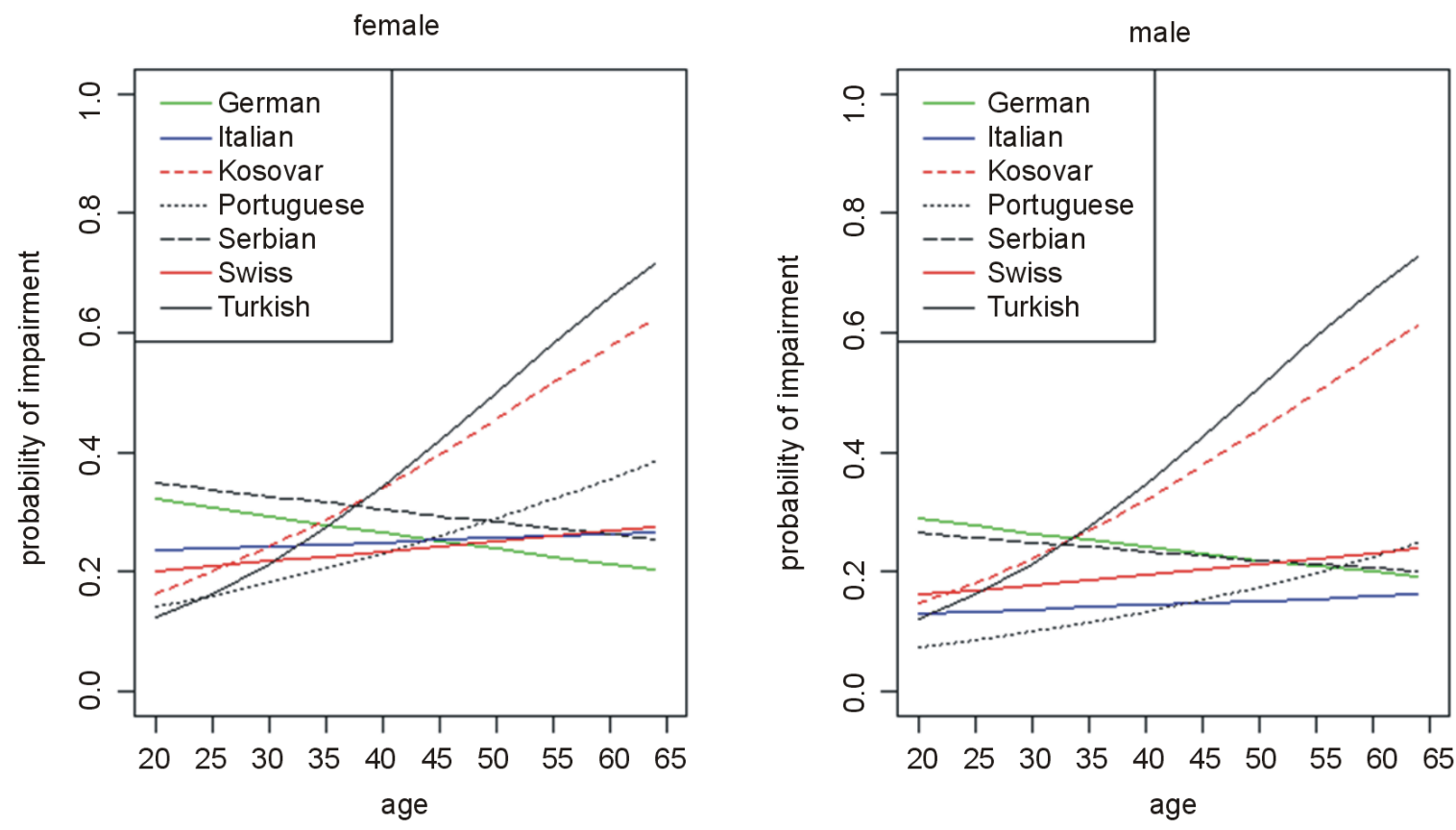

Figure 2. Probability of impairment (ADL) by age, gender and nationality ${ }^{*}$. All other covariates held constant (education = secondary, rooms/person $=1.5$, economically active $=$ yes, region $=$ rural area, sense of mastery $=$ medium, social support $=4.0)$. Significant differences between Swiss and immigrants from Turkey $(P=0.000)$ and immigrants from Kosovo $(\mathrm{P}=0.004)$. 
reported ill health and ADL impairments. Moreover, Portuguese women were more likely and German women were less likely to report ill health whereas women from Italy, Serbia, Turkey, and the Kosovo did not significantly differ from Swiss women. No significant differences between immigrant and Swiss women were found in the likelihood to report ADL impairments. Furthermore, the likelihood to report ill health did not significantly differ between immigrant and Swiss men. Similarly, reported ADL impairments did not significantly differ between immigrants from Serbia, Germany, Italy, and the Kosovo and Swiss men whereas Portuguese and Turkish men were less likely than Swiss men to report ADL impairments. In general, these results suggest that older immigrants from Turkey and the Kosovo as well as women from Portugal are at a particular risk of ill health and/or ADL impairments. Consequently, vulnerable immigrant groups in Switzerland should be addressed with immigrant-specific preventive and health promotion initiatives. Generally, our results are in line with previous studies that found no significant differences in self-reported health between German immigrants and Swiss but reported lower levels of health for immigrants from Turkey, Portugal, and the Former Yugoslavia which included immigrants from Kosovo and Serbia [14]. In contrast, we found no significant differences in health status between Italian immigrants and Swiss. The differences between study results may be attributed to the use of different health status indicators, i.e. we used self-reported health and ADL impairments whereas the reference study used indices of self-reported health (presence of chronic physical symptoms, lack of mental wellbeing).

Furthermore, previous studies find that higher socio-economic status [20] [52]-[56], coping strategies and a supportive social network are associated with better health. Our findings correspond to these results. Both, ill health and ADL impairments are consistently associated with low socioeconomic status, low sense of mastery and little social support. Preventive and health promotion initiatives should therefore also target specific groups with few economic and psychosocial resources in the general population of Switzerland. For groups with few economic resources, the cost of all preventive medical check-ups, e.g. mammography, should be fully covered by the compulsory health insurance. Moreover, preventive strategies and public health initiatives should take into account the specific information needs of immigrants and individuals with low education, i.e. the key message should be translated into the native languages of the most prevalent immigrant groups and the key messages should be clear and easy to understand.

Limitations in the present study need to be considered when interpreting the findings. First, even though selfrated health is strongly associated with mortality [57] and objective health status [58] [59], there is also evidence that the association between self-rated health and objective health status or mortality is weaker in less acculturated immigrants [60] [61]. Consequently, culture-specific connotations of health may bias our results despite the fact that we conducted a linguistic validation process that included a conceptual analysis of all original instruments in collaboration with the translators as well as forward and backward translations and a review of the backward translation. Second, data limitations did not permit a distinction between naturalized first-generation immigrants, naturalized offspring of first-generation immigrants and native Swiss. Therefore, part of the health advantage of Swiss nationals may be imported, i.e. immigrants with better health may be more likely to naturalize. Third, it should be considered that data collection for the Swiss, German and Italian population took place in 2007 whereas data for nationals form Portugal, Turkey, Serbia and the Kosovo was collected in 2010. Hence, potential bias due to cohort or period-specific effects cannot be ruled out. Further investigations should address these issues.

\section{Conclusion}

In sum, our results suggest that older immigrants from Turkey and the Kosovo as well as women from Portugal were at a particular risk of ill health and/or ADL impairments. Furthermore, poor health and ADL impairments were consistently associated with low socioeconomic status, low sense of mastery and little social support. Immigrant-specific preventive and health promotion initiatives should therefore target these immigrant groups. Furthermore, groups with few economic and psychosocial resources in the general population of Switzerland should be more involved in interventions to reduce health risk.

\section{Conflict of Interest}

The authors declare that they have no conflict of interest.

\section{Acknowledgments}

This study was supported by the Swiss Federal Office of Public Health and the Swiss Federal Office for Migra- 
tion, grant number 09.005923/704.0001/-330.

\section{References}

[1] Sole, M., Diaz-Serrano, L. and Rodriguez, M. (2013) Disparities in Work, Risk and Health between Immigrants and Native-Born Spaniards. Social Science \& Medicine, 76, 179-187. http://dx.doi.org/10.1016/j.socscimed.2012.10.022

[2] Quandt, S.A., Arcury-Quandt, A.E., Lawlor, E.J., Carrillo, L., Marin, A.J., Grzywacz, J.G. and Arcury, T.A. (2013) 3D Jobs and Health Disparities: The Health Implications of Latino Chicken Catchers' Working Conditions. American Journal of Industrial Medicine, 56, 206-215. http://dx.doi.org/10.1002/ajim.22072

[3] Jonkers, M., Richters, A., Zwart, J., Ory, F. and van Roosmalen, J. (2011) Severe Maternal Morbidity among Immigrant Women in the Netherlands: Patients' Perspectives. Reproductive Health Matters, 19, 144-153. http://dx.doi.org/10.1016/S0968-8080(11)37556-8

[4] Smaland Goth, U.G. and Berg, J.E. (2011) Migrant Participation in Norwegian Health Care. A Qualitative Study Using Key Informants. The European Journal of General Practice, 17, 28-33. http://dx.doi.org/10.3109/13814788.2010.525632

[5] Galanis, P., Sourtzi, P., Bellali, T., Theodorou, M., Karamitri, I., Siskou, O., Charalambous, G. and Kaitelidou, D. (2013) Public Health Services Knowledge and Utilization among Immigrants in Greece: A Cross-Sectional Study. BMC Health Services Research, 13, 350. http://dx.doi.org/10.1186/1472-6963-13-350

[6] Frank, A.L., Liebman, A.K., Ryder, B., Weir, M. and Arcury, T.A. (2013) Health Care access and Health Care Workforce for Immigrant Workers in the Agriculture, Forestry, and Fisheries Sector in the Southeastern US. American Journal of Industrial Medicine, 56, 960-974. http://dx.doi.org/10.1002/ajim.22183

[7] Koopmans, G.T., Uiters, E., Deville, W. and Foets, M. (2012) The Use of Outpatient Mental Health Care Services of Migrants vis-a-vis Dutch Natives: Equal Access? The International Journal of Social Psychiatry, 59, 342-350.

[8] Brussaard, J.H., van Erp-Baart, M.A., Brants, H.A., Hulshof, K.F. and Lowik, M.R. (2001) Nutrition and Health among Migrants in The Netherlands. Public Health Nutrition, 4, 659-664. http://dx.doi.org/10.1079/PHN2001149

[9] Ujcic-Voortman, J.K., Bos, G., Baan, C.A., Verhoeff, A.P. and Seidell, J.C. (2011) Obesity and Body Fat Distribution: Ethnic Differences and the Role of Socio-Economic Status. Obesity Facts, 4, 53-60.

[10] Wandell, P.E., Ponzer, S., Johansson, S.E., Sundquist, K. and Sundquist, J. (2004) Country of Birth and Body Mass Index: A National Study of 2000 Immigrants in Sweden. European Journal of Epidemiology, 19, 1005-1010. http://dx.doi.org/10.1007/s10654-004-0159-4

[11] Kirchengast, S. and Schober, E. (2006) Migration as Risk Factor of Overweight and Adipositas in Children and Adolescents. Anthropologischer Anzeiger, 64, 411-421.

[12] Kirchengast, S. and Schober, E. (2006) To Be an Immigrant: A Risk Factor for Developing Overweight and Obesity during Childhood and Adolescence? Journal of Biosocial Science, 38, 695-705. http://dx.doi.org/10.1017/S0021932005027094

[13] Abraido-Lanza, A.F., White, K., Armbrister, A.N. and Link, B.G. (2006) Health Status, Activity Limitations, and Disability in Work and Housework among Latinos and Non-Latinos with Arthritis: An Analysis of National Data. Arthritis and Rheumatism, 55, 442-450. http://dx.doi.org/10.1002/art.21981

[14] Bischoff, A. and Wanner, P. (2008) The Self-Reported Health of Immigrant Groups in Switzerland. Journal of Immigrant and Minority Health/Center for Minority Public Health, 10, 325-335.

[15] Jaeger, F.N., Hossain, M., Kiss, L. and Zimmerman, C. (2012) The Health of Migrant Children in Switzerland. International Journal of Public Health, 57, 659-671. http://dx.doi.org/10.1007/s00038-012-0375-8

[16] Sundquist, J. (1995) Ethnicity, Social Class and Health. A Population-Based Study on the Influence of Social Factors on Self-Reported Illness in 223 Latin American Refugees, 333 Finnish and 126 South European Labour Migrants and 841 Swedish Controls. Social Science \& Medicine, 40, 777-787. http://dx.doi.org/10.1016/0277-9536(94)00146-K

[17] Sundquist, J. (1995) Living Conditions and Health: A Population-Based Study of Labour Migrants and Latin American Refugees in Sweden and Those Who Were Repatriated. Scandinavian Journal of Primary Health Care, 13, 128-134. http://dx.doi.org/10.3109/02813439508996749

[18] de Wit, M.A., Tuinebreijer, W.C., Dekker, J., Beekman, A.J., Gorissen, W.H., Schrier, A.C., Penninx, B.W., Komproe, I.H. and Verhoeff, A.P. (2008) Depressive and Anxiety Disorders in Different Ethnic Groups: A Population Based Study among Native Dutch, and Turkish, Moroccan and Surinamese Migrants in Amsterdam. Social Psychiatry and Psychiatric Epidemiology, 43, 905-912. http://dx.doi.org/10.1007/s00127-008-0382-5

[19] Anikeeva, O., Bi, P., Hiller, J.E., Ryan, P., Roder, D. and Han, G.S. (2010) The Health Status of Migrants in Australia: A Review. Asia-Pacific Journal of Public Health/Asia-Pacific Academic Consortium for Public Health, 22, 159-193. 
[20] Abraido-Lanza, A.F., Dohrenwend, B.P., Ng-Mak, D.S. and Turner, J.B. (1999) The Latino Mortality Paradox: A Test of the "Salmon Bias" and Healthy Migrant Hypotheses. American Journal of Public Health, 89, 1543-1548. http://dx.doi.org/10.2105/AJPH.89.10.1543

[21] Norredam, M., Olsbjerg, M., Petersen, J.H., Juel, K. and Krasnik, A. (2012) Inequalities in Mortality among Refugees and Immigrants Compared to Native Danes-A Historical Prospective Cohort Study. BMC Public Health, $12,757$. http://dx.doi.org/10.1186/1471-2458-12-757

[22] Mejean, C., Traissac, P., Eymard-Duvernay, S., El Ati, J., Delpeuch, F. and Maire, B. (2007) Influence of Socio-Economic and Lifestyle Factors on Overweight and Nutrition-Related Diseases among Tunisian Migrants versus Non-Migrant Tunisians and French. BMC Public Health, 7, 265. http://dx.doi.org/10.1186/1471-2458-7-265

[23] Akresh, I.R. (2008) Overweight and Obesity among Foreign-Born and U.S.-Born Hispanics. Biodemography and Social Biology, 54, 183-199. http://dx.doi.org/10.1080/19485565.2008.9989141

[24] Kumar, N.B., Yu, D., Akinremi, T.O. and Odedina, F.T. (2009) Comparing Dietary and Other Lifestyle Factors among Immigrant Nigerian Men Living in the US and Indigenous Men from Nigeria: Potential Implications for Prostate Cancer Risk Reduction. Journal of Immigrant and Minority Health/Center for Minority Public Health, 11, 391-399.

[25] Harriss, L.R., English, D.R., Powles, J., Giles, G.G., Tonkin, A.M., Hodge, A.M., Brazionis, L. and O’Dea, K. (2007) Dietary Patterns and Cardiovascular Mortality in the Melbourne Collaborative Cohort Study. The American Journal of Clinical Nutrition, 86, 221-229.

[26] Neuhouser, M.L., Thompson, B., Coronado, G.D. and Solomon, C.C. (2004) Higher Fat Intake and Lower Fruit and Vegetables Intakes Are Associated with Greater Acculturation among Mexicans Living in Washington State. Journal of the American Dietetic Association, 104, 51-57. http://dx.doi.org/10.1016/j.jada.2003.10.015

[27] Renzaho, A.M., Swinburn, B. and Burns, C. (2008) Maintenance of Traditional Cultural Orientation Is Associated with Lower Rates of Obesity and Sedentary Behaviours among African Migrant Children to Australia. International Journal of Obesity, 32, 594-600. http://dx.doi.org/10.1038/ijo.2008.2

[28] Satia-Abouta, J., Patterson, R.E., Kristal, A.R., Teh, C. and Tu, S.P. (2002) Psychosocial Predictors of Diet and Acculturation in Chinese American and Chinese Canadian Women. Ethnicity \& Health, 7, 21-39. http://dx.doi.org/10.1080/13557850220146975

[29] Landman, J. and Cruickshank, J.K. (2001) A Review of Ethnicity, Health and Nutrition-Related Diseases in Relation to Migration in the United Kingdom. Public Health Nutrition, 4, 647-657. http://dx.doi.org/10.1079/PHN2001148

[30] Marques-Vidal, P., Vollenweider, P., Waeber, G. and Paccaud, F. (2011) Prevalence of Overweight and Obesity among Migrants in Switzerland: Association with Country of Origin. Public Health Nutrition, 14, 1148-1156. http://dx.doi.org/10.1017/S1368980011000103

[31] Vaillant, N. and Wolff, F.C. (2010) Origin Differences in Self-Reported Health among Older Migrants Living in France. Public Health, 124, 90-98. http://dx.doi.org/10.1016/j.puhe.2010.01.005

[32] Weilandt, C., Rommel, A., Eckert, J. and Gall Azmat, R. (2006) Health Monitoring of the Swiss Migrant Population. Bundesgesundheitsblatt, Gesundheitsforschung, Gesundheitsschutz, 49, 866-872. http://dx.doi.org/10.1007/s00103-006-0020-x

[33] Lert, F., Melchior, M. and Ville, I. (2007) Functional limitations and Overweight among Migrants in the Histoire de Vie Study (Insee, 2003). Revue d'Epidemiologie et de Sante Publique, 55, 391-400. http://dx.doi.org/10.1016/j.respe.2007.09.003

[34] Tarnutzer, S. and Bopp, M. (2012) Healthy Migrants but Unhealthy Offspring? A Retrospective Cohort Study among Italians in Switzerland. BMC Public Health, 12, 1104. http://dx.doi.org/10.1186/1471-2458-12-1104

[35] Stirbu, I., Kunst, A.E., Bos, V. and Mackenbach, J.P. (2006) Differences in Avoidable Mortality between Migrants and the Native Dutch in the Netherlands. BMC Public Health, 6, 78. http://dx.doi.org/10.1186/1471-2458-6-78

[36] Stirbu, I., Kunst, A.E., Vlems, F.A., Visser, O., Bos, V., Deville, W., Nijhuis, H.G. and Coebergh, J.W. (2006) Cancer Mortality Rates among First and Second Generation Migrants in the Netherlands: Convergence toward the Rates of the native Dutch population. International Journal of Cancer. Journal International du Cancer, 119, 2665-2672.

[37] Rasulo, D., Spadea, T., Onorati, R. and Costa, G. (2012) The Impact of Migration in All-Cause Mortality: The Turin Longitudinal Study, 1971-2005. Social Science \& Medicine, 74, 897-906. http://dx.doi.org/10.1016/j.socscimed.2011.10.045

[38] Caperchione, C.M., Kolt, G.S. and Mummery, W.K. (2009) Physical Activity in Culturally and Linguistically Diverse Migrant Groups to Western Society: A Review of Barriers, Enablers and Experiences. Sports Medicine, 39, 167-177. http://dx.doi.org/10.2165/00007256-200939030-00001

[39] Ceballos, N. and Czyzewska, M. (2010) Body Image in Hispanic/Latino vs. European American Adolescents: Implications for Treatment and Prevention of Obesity in Underserved Populations. Journal of Health Care for the Poor and Underserved, 21, 823-838. http://dx.doi.org/10.1353/hpu.0.0333 
[40] Kolcic, I. and Polasek, O. (2009) Healthy Migrant Effect within Croatia. Collegium Antropologicum, 33, 141-145.

[41] Liu, J.H., Probst, J.C., Harun, N., Bennett, K.J. and Torres, M.E. (2009) Acculturation, Physical Activity, and Obesity among Hispanic Adolescents. Ethnicity \& Health, 14, 509-525. http://dx.doi.org/10.1080/13557850902890209

[42] Park, S.Y., Murphy, S.P., Sharma, S. and Kolonel, L.N. (2005) Dietary Intakes and Health-Related Behaviours of Korean American Women Born in the USA and Korea: The Multiethnic Cohort Study. Public Health Nutrition, 8, 904911. http://dx.doi.org/10.1079/PHN2005740

[43] Olvera, N., Suminski, R. and Power, T.G. (2005) Intergenerational Perceptions of Body Image in Hispanics: Role of BMI, Gender, and Acculturation. Obesity Research, 13, 1970-1979. http://dx.doi.org/10.1038/oby.2005.242

[44] Nicolaou, M., Doak, C.M., van Dam, R.M., Brug, J., Stronks, K. and Seidell, J.C. (2009) Cultural and Social Influences on Food Consumption in Dutch Residents of Turkish and Moroccan Origin: A Qualitative Study. Journal of Nutrition Education and Behavior, 41, 232-241. http://dx.doi.org/10.1016/j.jneb.2008.05.011

[45] Abraido-Lanza, A.F., Armbrister, A.N., Florez, K.R. and Aguirre, A.N. (2006) Toward a Theory-Driven Model of Acculturation in Public Health Research. American Journal of Public Health, 96, 1342-1346. http://dx.doi.org/10.2105/AJPH.2005.064980

[46] Bhopal, R. (2009) Chronic Diseases in Europe’s Migrant and Ethnic Minorities: Challenges, Solutions and a Vision. European Journal of Public Health, 19, 140-143. http://dx.doi.org/10.1093/eurpub/ckp024

[47] Bhopal, R. and Rafnsson, S. (2012) Global Inequalities in Assessment of Migrant and Ethnic Variations in Health. Public Health, 126, 241-244. http://dx.doi.org/10.1016/j.puhe.2011.11.016

[48] BFS (2010) Statistik der Bevölkerung und der Haushalte (STATPOP). Swiss Federal Statistical Office, Neuchâtel.

[49] Moser, D.K. and Dracup, K. (1995) Psychosocial Recovery from a Cardiac Event: The Influence of Perceived Control. Heart \& Lung: The Journal of Critical Care, 24, 273-280.

[50] Pearlin, L.I. and Schooler, C. (1978) The Structure of Coping. Journal of Health and Social Behavior, 19, 2-21. http://dx.doi.org/10.2307/2136319

[51] Grossmann, F., Leventhal, M.E., Auer-Böer, B., Wanner, P. and Bischoff, A. (2011) Self-Reported Cardiovascular Risk Factors in Immigrants and Swiss Nationals. Public Health Nursing, 28, 129-139. http://dx.doi.org/10.1111/j.1525-1446.2010.00896.x

[52] Marmot, M.G., Kogevinas, M. and Elston, M.A. (1991) Socioeconomic Status and Disease. WHO Regional Publications European Series, 37, 113-146.

[53] Marmot, M.G., Shipley, M.J. and Rose, G. (1984) Inequalities in Death-Specific Explanations of a General Pattern? Lancet, 323, 1003-1006. http://dx.doi.org/10.1016/S0140-6736(84)92337-7

[54] Marmot, M.G., Smith, G.D., Stansfeld, S., Patel, C., North, F., Head, J., White, I., Brunner, E., Feeney, A., Marmot, M.G. and Smith, G.D. (1991) Health Inequalities among British Civil Servants: The Whitehall II Study. Lancet, 337, 1387-1393. http://dx.doi.org/10.1016/0140-6736(91)93068-K

[55] Quon, E.C. and McGrath, J.J. (2014) Subjective Socioeconomic Status and Adolescent Health: A Meta-Analysis. Health Psychology: Official Journal of the Division of Health Psychology, American Psychological Association, 33, 433-447.

[56] Cundiff, J.M., Uchino, B.N., Smith, T.W. and Birmingham, W. (2013) Socioeconomic Status and Health: Education and Income Are Independent and Joint Predictors of Ambulatory Blood Pressure. Journal of Behavioral Medicine, 1-8. http://dx.doi.org/10.1007/s10865-013-9515-8

[57] DeSalvo, K.B., Bloser, N., Reynolds, K., He, J. and Muntner, P. (2006) Mortality Prediction with a Single General Self-Rated Health Question. A Meta-Analysis. Journal of General Internal Medicine, 21, 267-275. http://dx.doi.org/10.1111/j.1525-1497.2005.00291.X

[58] Haddock, C.K., Poston, W.S., Pyle, S.A., Klesges, R.C., Vander Weg, M.W., Peterson, A. and Debon, M. (2006) The Validity of Self-Rated Health as a Measure of Health Status among Young Military Personnel: Evidence from a CrossSectional Survey. Health and Quality of Life Outcomes, 4, 57. http://dx.doi.org/10.1186/1477-7525-4-57

[59] Trump, D.H. (2006) Self-Rated Health and Health Care Utilization after Military Deployments. Military Medicine, 171, 662-668.

[60] Finch, B.K., Hummer, R.A., Reindl, M. and Vega, W.A. (2002) Validity of Self-Rated Health among Latino(a)s. American Journal of Epidemiology, 155, 755-759. http://dx.doi.org/10.1093/aje/155.8.755

[61] Agyemang, C., Denktas, S., Bruijnzeels, M. and Foets, M. (2006) Validity of the Single-Item Question on Self-Rated Health Status in First Generation Turkish and Moroccans versus Native Dutch in the Netherlands. Public Health, 120, 543-550. http://dx.doi.org/10.1016/j.puhe.2006.03.002 